\title{
Los derechos y la interpretación constitucional: la mutación en construcción
}

Rights and constitutional interpretation: the mutation under construction

\section{Direitos e interpretação constitucional: a mutação em construção}

Gianella Bardazano

Prof. Agr. (grado 4) de Filosofía del Derecho (Udelar) Contacto: gianella.bardazano@fder.edu.uy

\section{Resumen}

La Constitución nacional de 1917 incorpora en su artículo 173 una cláusula de derechos implícitos - el actual artículo 72- que establece que la enunciación de derechos hecha por la Constitución no es taxativa. El objetivo de este trabajo es describir panorámicamente y analizar las lecturas dogmáticas de la cláusula de derechos implícitos, teniendo en cuenta su impacto en la comprensión de las fuentes del derecho y de la función de los tribunales. Desde el punto de vista de la teoría de la interpretación jurídica (Guastini, 2012), las construcciones dogmáticas contribuyen a invisibilizar el componente político de la interpretación constitucional. En ese sentido, la sustitución de la dogmática formalista por la dogmática neoconstitucionalista con relación a la interpretación constitucional, sin mediar teorización, tiende a negar la diferencia entre legislación y jurisdicción, en la medida en que presenta como aplicación de las disposiciones constitucionales la atribución de un sentido determinado a compromisos constitucionales expresados en enunciados que contienen conceptos polémicos (Atria, 2016), al tiempo que la determinación del alcance de las disposiciones constitucionales constituye un juicio político acerca de los desarrollos concretos de los principios fundamentales que compartimos como comunidad política.

Palabras clave: Constitución, interpretación, dogmática, fuentes, jurisdicción 


\begin{abstract}
The national Constitution of 1917 incorporates in article 173 an implied rights clause - the current article 72 - which states that the enunciation of rights made in the Constitution is not exhaustive. The aim of the article is to describe and analyze the dogmatic readings of the implied rights clause, taking into account their impact on the understanding of the sources of law and the function of courts. From the point of view of the theory of legal interpretation (Guastini 2012), dogmatic constructions contribute to the invisibility of the political component of constitutional interpretation. Therefore, the substitution of formalist dogmatics by neo-constitutionalist dogmatics in relation to constitutional interpretation, without theorization, tends to deny the difference between legislation and jurisdiction, because it presents as application of the constitutional provisions the attribution of a specific meaning to statements that contain controversial concepts (Atria, 2016). Hence, the determination of the scope of the constitutional provisions involves political judgment about the specific developments of the fundamental principles that we share as a political community.
\end{abstract}

Keywords: Constitution, interpretation, dogmatics, sources, jurisdiction

\title{
Resumo
}

A Constituição nacional de 1917 incorpora no artigo 173 uma cláusula de direitos implícitos —o atual artigo 72- que estabelece que a enunciação de direitos feita pela Constituição não é taxativa. 0 objetivo deste artigo é descrever de maneira panorâmica e analisar as leituras dogmáticas da cláusula de direitos implícitos, levando em conta seu impacto na compreensão das fontes de direito e da função dos tribunais. Desde o ponto de vista da teoria da interpretação jurídica (Guastini 2012), as construções dogmáticas contribuem para ocultar o componente político da interpretação constitucional. Nesse sentido, a substituição da dogmática formalista pela dogmática neoconstitucionalista em relação à interpretação constitucional, sem mediar teorização, tende a negar a diferença entre legislação e jurisdição, na medida em que apresenta como aplicação das disposições constitucionais a atribuição de um sentido determinado a compromissos constitucionais expressos em enunciados que contêm conceitos polêmicos (Atria, 2016), à medida que a determinação do alcance das disposições constitucionais constitui um juízo político acerca dos desenvolvimentos concretos dos princípios fundamentais que compartilhamos como comunidade política.

Palavras-chave: Constituição, interpretação, dogmática, fontes, jurisdição 


\section{Introducción}

La ampliación del elenco de derechos en los ordenamientos jurídicos ha operado mediante diferentes técnicas. En algunos casos recientes, lo ha hecho a través de la constitucionalización expresa de instrumentos internacionales de derechos humanos ${ }^{1}$ o del establecimiento de una densa carta de derechos en el texto constitucional. ${ }^{2}$ Algunos países han recurrido a ambas técnicas ${ }^{3}$ (Uprimny, 2011). En otros, la constitucionalización ha sido implícita y, por tanto, dependiente de la consolidación de la recepción de la doctrina del bloque de constitucionalidad por los tribunales o de otras técnicas interpretativas; en ese sentido, la dogmática constitucional la relaciona con la noción de interpretación evolutiva (Risso, 2017) o con la de mutación constitucional (Hesse, 1983; De Vega, 1985; Rollnert Liern, 2014).

La Constitución nacional de 1917 incorpora en su artículo 173 una cláusula de derechos implícitos - el actual artículo 72- que establece que la enunciación de derechos hecha por la Constitución no es taxativa. El objetivo de este trabajo es describir panorámicamente y analizar las lecturas dogmáticas de la cláusula de derechos implícitos, teniendo en cuenta su impacto en la comprensión de las fuentes del derecho y de la función de los tribunales.

Desde el punto de vista de la teoría de la interpretación jurídica (Guastini, 2012), las construcciones dogmáticas contribuyen a invisibilizar el componente político de la interpretación constitucional. En ese sentido, la sustitución de la dogmática formalista por la dogmática neoconstitucionalista con relación a la interpretación constitucional, sin mediar teorización, tiende a negar la diferencia entre legislación y jurisdicción, en la medida en que presenta como aplicación de las disposiciones constitucionales la atribución de un sentido determinado a compromisos constitucionales expresados en enunciados que contienen conceptos polémicos (Atria, 2016), al tiempo que la determinación del alcance de las disposiciones constitucionales constituye un juicio político acerca de los desarrollos concretos de los principios fundamentales que compartimos como comunidad política.

\section{El lugar del actual artículo 72 en la Convención Constituyente de $1917^{4}$}

En sesión de 22 de noviembre de 1916 se da cuenta a la Convención del proyecto de la Comisión Especial de Constituyentes Nacionalistas — presidida por Vásquez Acevedo—, remitido a la presidencia de la Convención días antes. El último artículo de la sección XI («Derechos y garantías») incluido en dicho proyecto es el 166: «La enumeración de derechos y garantías hechos [sic] por la Constitución no excluye los otros que son inherentes a la personalidad humana o se derivan de la forma republicana de gobierno» (Convención Nacional Constituyente, 1918 [tomo I]:192).

En la misma sesión, se da cuenta de la presentación del proyecto de Vásquez Acevedo, 5 quien en nota fechada el 10 de noviembre de 1916 aclara que si bien suscribió el proyecto nacionalista, dejó expresa constancia de sus discrepancias, y que el documento que presenta incorpora las reformas que

ANUARIO DEL ÁREA SOCIO-JURÍDICA | MONTEVIDEO - URUGUAY | v. 10 | n. 1 | p. 01-15 | DEZ. 2018 
entiende fundamentales y no fueron tenidas en cuenta por el proyecto nacionalista. ${ }^{6}$ El texto prevé, en el artículo 149: «La enumeración de derechos y garantías hecha por la Constitución no excluye los que son inherentes a la personalidad humana o se derivan de la forma republicana de gobierno» (Convención Nacional Constituyente, 1918 [tomo I]:219). ${ }^{7}$

En la sesión de 24 de noviembre de 1916, Antonio María Rodríguez ${ }^{8}$ presenta el proyecto del fallecido Enrique Azarola, elaborado en 1905, que incluye en su capítulo XIV9 el artículo 224, con la siguiente redacción:

Las declaraciones de principios y garantías a los derechos individuales hechas en este capítulo no se entenderán como una negación o restricción de otros principios o garantías no señaladas expresamente, pero que deriven de la soberanía del pueblo y de la forma republicana democrática de los poderes públicos.10

El 1 de octubre de 1917 se remite a la Convención el proyecto elaborado por la Comisión de Constitución, ${ }^{\mathbf{1 1}}$ el que es sometido a discusión particular dos semanas más tarde. La redacción del artículo 173 es la siguiente: «La enumeración de derechos y garantías hecha por la Constitución no excluye los otros que son inherentes a la personalidad humana o se derivan de la forma republicana de gobierno» (Convención Nacional Constituyente, 1918 [tomo III]:418). La disposición es aprobada sin discusión.12

\section{La recepción por la dogmática}

La práctica jurídica la conforman los juristas y jueces, quienes pueden considerarse «la clase interpretadora» que emplea determinadas herramientas - métodos interpretativos, dogmática jurídicay esquemas conceptuales, a la vez que está embebida de preferencias ético-políticas (Bouvier, 2012:170-171), y genera variedad de interpretaciones. La influencia de la doctrina producida por los juristas en la interpretación judicial, su capacidad de moldear la forma de pensamiento de los jueces, puede describirse a través de una reconstrucción —-necesariamente parcial e incompleta- de la historia hermenéutica del artículo 72.

En 1946 afirmaba Jiménez de Aréchaga que «los fines de un sistema jurídico son los principios generales sobre los cuales ese sistema jurídico se construye. Pero recordamos [...] con Carnelutti que los principios generales del derecho deben buscarse en el derecho positivo mismo y no en los sueños o en las doctrinas de los juristas» (1946:107-108). El sentido finalista de nuestra Constitución se orienta al «aseguramiento de la convivencia pacífica, bajo el derecho, de todos los habitantes comprendidos en su territorio, asegurando su libertad por la independencia de la república, gobernada democráticamente» (1946:108). Se pregunta entonces cuáles son las bases éticas y culturales sobre las que se asienta la estructura jurídica nacional: «Debe decirse, en primer lugar, que la Constitución recibe y consagra una concepción de tipo iusnaturalista, y esto solo basta para que pueda rechazarse la aplicación de los métodos jurídico-formales a su interpretación». En el artículo 63 de la Constitución de 1942 se declara 
que «el hombre posee derechos inherentes a su personalidad», de modo que «cualesquiera sean las reservas que en la especulación doctrinaria puedan merecer a algunos las teorías del derecho natural, debe reconocerse que ellas están incorporadas al régimen de nuestra Constitución por texto expreso», porque «no se puede decir que el hombre posee derechos inherentes a su personalidad sin admitir que, por encima del orden jurídico positivo, existe un orden jurídico natural» (1946:108). La regla interpretativa que entiende se deriva de lo anterior requiere que la sección II de la Constitución no se conciba como constitutiva de derechos, sino declarativa, y que la enumeración de derechos no es exhaustiva, sino meramente enunciativa de los principales derechos del individuo (1946:109).

En 1957, Sampay ${ }^{13}$ señala que la inconstitucionalidad en razón de contenido opera cuando una ley «contraviene un derecho subjetivo concedido expresa o implícitamente por la Constitución», en tanto la enumeración de derechos no es taxativa (1957:25). En su análisis del artículo 72 sostiene:

a. Que «la forma republicana de gobierno es aquella en la cual los ciudadanos gozan del derecho de participar en el manejo de la cosa pública, eligiendo a los gobernantes y pudiendo ser elegidos a su vez como tales; y por medio de la fiscalización de las gestiones que realizan los poderes públicos». Así, concluye que «sería inconstitucional la norma jurídica que menoscabe cualquier derecho subjetivo emergente de los principios de libertad e igualdad políticas, aun cuando ese derecho no se encontrara nombrado por el texto constitucional» (1957:26).

b. Que con la referencia a los derechos que «son inherentes a la personalidad humana» se incorporan «al orden jurídico positivo todos los preceptos que por vía de conclusión derivan de los principios generales de la ley natural» (1957:26). A su vez, señala que «la fórmula atesora una magnífica tradición teórica y constituye el alma de la cultura jurídica de Occidente. Trae su origen de Aristóteles [...]; Cicerón [...]; Santo Tomás [...]; también la hacen suyas Leibniz y Montesquieu, y en todo tiempo la adoptan las filosofías asentadas en el realismo ontológico» (1957:27). En definitiva, el sentido que le atribuye a la disposición asume la tesis metodológica del iusnaturalismo, es decir, la de que una norma no puede ser jurídicamente válida si contradice los principios del derecho natural.

La interpretación que propone Real es la de que la redacción uruguaya se aparta de los modelos estadounidense y argentino «en cuanto incluye en su letra, clarísima, la evidente recepción del jusnaturalismo personalista, que aquellos solo suponen implícita en su espíritu» (2001:46). Agrega que la enmienda IX de la Constitución de Estados Unidos dejaba a salvo «otros derechos conservados por el pueblo», expresión que podía ser interpretada como referida a los derechos políticos «más que a los derechos humanos propiamente dichos» (2001:46). Por su parte, la Constitución argentina hace referencia a los derechos y garantías «que nacen de la soberanía del pueblo y de la forma republicana de gobierno»,14 lo cual literalmente, entiende Real, también conduce a una interpretación restrictiva. Real, en definitiva, se suma a la interpretación propuesta un año antes por Sampay en cuanto a que la fórmula uruguaya, al agregar la expresión «los otros que son inherentes a la personalidad humana», hace «indiscutible la recepción del iusnaturalismo en nuestro derecho constitucional» (2001:46). Reafirma que los derechos fundamentales de la persona «mantienen su valor de supremos postulados finalistas a lograr 
por los órdenes jurídicos nacionales, no obstante la disminución de la autonomía individual que ha producido la expansión» del Estado de bienestar «intervencionista, socializante, planificador y burocrático».15 A su vez, ese «ideal común de la humanidad encuentra su expresión en la Declaración Universal de Derechos del Hombre de 1948 (2001:52-53).

A propósito de la interpretación constitucional, Real sostiene que recurrir a «la axiología iusnaturalista, lejos de ser un pecado contra el positivismo o formalismo jurídico, es una imposición del mismo, cuando son los propios textos de la Constitución escrita los que se remiten a las pautas estimativas de humanismo jurídico como "filosofía del régimen"».16 Es lo que ocurre en Uruguay con el artículo 72 (Real, 1979:67). La finalidad esencial del Estado de derecho es tutelar los derechos humanos, y se expresa en la «clarísima recepción constitucional del personalismo democrático republicano» (Real, 1974:125). ${ }^{17}$ Real formula directivas para los intérpretes aplicadores y también para la dogmática cuando sostiene que la redacción del artículo 72, coordinada con la del 82, «convierte [las] elevadas finalidades del iusnaturalismo liberal18 [...] en principios generales del derecho positivo, de trascendencia práctica, de los que no puede prescindir la sistematización técnico-jurídica» (1974:126).

Como contenidos normativos implícitos y no taxativos del artículo 72, Real relevaba en las decisiones de los tribunales hasta 1958 los siguientes: el principio de igualdad ante las cargas públicas, el principio de igualdad ante los servicios públicos, la obligación de indemnizar el enriquecimiento injusto a expensas de otro, la responsabilidad del Estado por acto legislativo, el derecho a la defensa como un aspecto particular de la garantía del debido proceso, el non bis in ídem en materia disciplinaria, la obligación de decidir expresamente peticiones y recursos, el derecho al nombre y el derecho al uso exclusivo de la propia imagen (2001:55-73); agregaba el derecho a la personalidad jurídica, el derecho a la indemnización del daño moral, el derecho moral de autores e inventores, la legítima defensa, la irretroactividad de la ley penal y la resistencia a la opresión (2001:73-78).

En 1996, Cajarville sostiene que el artículo 72 afirma la existencia de «derechos, deberes y garantías» que no han sido enumerados en la Constitución, y esa disposición los incorpora al derecho positivo. Se trata de verdaderas situaciones jurídicas que resultan de normas jurídicas; esas normas jurídicas son los principios generales del derecho que, a su vez, son expresamente aludidos en el artículo 332 (2001:132-133). Ahora bien, los principios aludidos por el artículo 72 tienen que ver con derechos, deberes y garantías no enumerados en las disposiciones constitucionales, en tanto los aludidos en el artículo 332 refieren a los derechos expresamente reconocidos en una disposición constitucional, y también a las facultades y deberes de las autoridades públicas (no mentadas en el artículo 72). ${ }^{19} \mathrm{Se}$ distancia de la interpretación de Real en la medida en que sostiene que

cuando se trata de determinar concretamente cuáles sean esos principios generales del derecho positivizados por el artículo 72, nada obliga a considerar que sean los que derivan de la personalidad humana o de cierta forma de gobierno tal como fueron concebidas por determinada corriente de pensamiento en cierto momento histórico [...]. El artículo 72 entraña sin duda la admisión de una concepción iusnaturalista [...], pero toda apelación a la «naturaleza de las cosas» debe tener presente que esa naturaleza [...] opera siempre por el trámite de una representación que se hace de ella la conciencia social históricamente determinada, y, por ello, a través de una visión y una valoración históricamente condicionada. (2001:139) 
El iusnaturalismo es, entonces, un instrumento de interpretación e integración del derecho positivo, incorporado por el propio derecho positivo (2001:140). Dependerá de la cultura jurídica dominante cuáles sean esos principios generales que, en tanto son considerados el contenido implícito de una disposición constitucional, tienen jerarquía constitucional (2001:144). ${ }^{20}$ En cuanto a las convenciones y tratados sobre derechos humanos, señala que su contenido debe analizarse a la luz del artículo 72 :

El perfeccionamiento internacional del tratado o convención y su aprobación y ratificación por el país comprueban la convicción socialmente dominante en el ámbito nacional, e incluso en el internacional comprendido por el tratado, sobre la existencia de los derechos en él reconocidos, o si se prefiere, su consagración por el «derecho natural»; y en cuanto esos derechos puedan predicarse de todo individuo por igual y en la misma medida [...], en cuanto [dependan] de su propia naturaleza, de lo que tiene en común con todos los hombres, deberá considerarse un derecho «inherente a la personalidad», contenido en un principio general de jerarquía constitucional en virtud del artículo 72 [...]. Por lo tanto, una ley nacional que desconozca ese derecho será inconstitucional y pasible de desaplicación, previa declaración por la Suprema Corte de Justicia, no por contrariar el tratado o convención internacional, sino por contrariar un principio general de jerarquía constitucional. (2001:144-145)

Risso (2015) retoma esa aproximación entre el derecho constitucional y el derecho internacional, y señala, refiriendo al giro producido en los años noventa, que en medio del proceso que en el derecho comparado ha llevado a la constitucionalización del derecho internacional de los derechos humanos,

el artículo 72 [...] fue en los hechos reinterpretado, en el sentido de que dicha disposición constituía la puerta de ingreso de todos los derechos contenidos en el derecho internacional de los derechos humanos, con base en textos provenientes de 1918 y que, sin duda, en ningún momento sugirieron a sus autores esa posibilidad. (2015:33)

La elaboración de la construcción jurídica de la «constitucionalización» del derecho internacional de los derechos humanos permitió laudar discusiones acerca de la jerarquía y la aplicación en el ámbito interno de las normas internacionales. Pero incluir esos instrumentos en la Constitución habilitaba que el poder constituyente de cada Estado los «desconstitucionalizase» (2015:34). Esa preocupación es el germen de la elaboración de la doctrina que sostiene la

existencia de un bloque de derechos integrado por los derechos asegurados explícitamente en el texto constitucional, los derechos contenidos en los instrumentos internacionales de derechos humanos y los derechos implícitos, donde el operador jurídico debe interpretar los derechos buscando preferir aquella fuente que mejor protege y garantiza los derechos de la persona humana, (Nogueira, 2003:422)

lo que elimina la incidencia de la potestad estatal constituyente en la limitación de la protección. En ese sentido, dando cuenta de la interpretación evolutiva de la disposición a partir de nuevas circunstancias y 
necesidades (2017:244), Risso entiende que la reinterpretación del artículo 72 que se produjo en los años noventa proponiendo la constitucionalización del derecho internacional de los derechos humanos ha sido superada por

una nueva noción que fusiona la regulación internacional y constitucional de los derechos humanos en un bloque que se complementa perfectamente y que no se rige por el principio de jerarquía, sino por la directriz de preferencia de normas (si dos normas regulan un derecho o una garantía, hay que preferir la que mejor lo protege, la que le da mayor amplitud) y por la directriz de preferencia de interpretaciones (cuando una norma de derechos humanos sea susceptible de varias interpretaciones razonables, deberá elegirse aquella que mejor proteja y garantice el derecho en juego). (2015:37)

Al respecto señala que la mencionada reinterpretación se encuentra «en el límite entre la interpretación evolutiva que se mantiene dentro de las pautas constitucionales (constitucionalismo viviente) y la mutación en sentido estricto» (2017:244).21

\section{Consecuencias prácticas de los distintos alcances de la disposición}

Los conceptos empleados en la formulación de principios constitucionales, entonces, son altamente indeterminados; para su concretización, los intérpretes apelan a doctrinas morales, concepciones filosóficas o ideologías políticas. Entender el artículo 72 como una norma de reenvío a la doctrina iusnaturalista, a la moral social o a la moral crítica no transforma al iusnaturalismo en derecho positivo ni a la moral en derecho, pero ha permitido extender la protección de derechos. En términos teóricos, siguiendo a Guastini $(2012,2014,2016)$, la operación que estamos describiendo no es un ejemplo de interpretación constitucional, sino un ejemplo de construcción jurídica. Nos permite ver cómo las soluciones creadas por la dogmática le son atribuidas a la Constitución o a la voluntad constituyente y la función normativa de la dogmática, a pesar del talante descriptivo de sus enunciados interpretativos.

La importancia de la operación dogmática y sus inconmensurables derivaciones prácticas puede ilustrarse evocando la justificación que el Cnel. Federico Silva Ledesma ${ }^{22}$ encontraba en el artículo 72 para recibir en el texto constitucional al estado de necesidad como principio del derecho y, en ese sentido, como fundamento del golpe de Estado de 1973. Sostenía:

El estado de necesidad es de recibo en nuestro texto constitucional [...]. La disolución del parlamento, la actitud adoptada por el Poder Ejecutivo primero, la ley de seguridad del Estado, ley más severa que las demás, pueden tener explicación perfectamente por la norma amplia de integración del artículo 72 de la Constitución, de la Constitución vigente. (Silva Ledesma, 1977:22) ${ }^{23}$ 
En sentido contrario, Rotondo ha sostenido que los límites de los principios implícitos del artículo 72 están constituidos por el sistema jurídico constitucional, «llevando al respeto de los derechos, al cumplimiento de los deberes correlativos y de los deberes-poderes de las autoridades, sin que estas puedan, por vía del art. 72, soslayar [...] los principios orgánicos y dogmáticos consagrados en forma expresa por la Constitución» (Rotondo, 2017:70), lo cual implicaría ir en contra del fundamento mismo del artículo 72. Ambas lecturas, cuyas consecuencias normativas son claramente antagónicas, dan cuenta de la relevancia del compromiso de los intérpretes con un tipo de Estado y una determinada concepción de los derechos y deberes.

En definitiva, la cuestión de si se crean o declaran los derechos es más una cuestión de opciones filosófico-jurídicas con consecuencias prácticas que de interpretación constitucional. Vimos que la elaboración dogmática nacional asume, a partir de la letra de la Constitución, que los derechos son declarados, de manera que en el artículo 72 habría una disposición que expresa una tesis filosóficopolítica (Guastini, 2016:77). En general, del panorama de la interpretación dogmática que fue presentado surge la comprensión de los derechos como existentes, en tanto derechos naturales, antes de la Constitución que los reconoce y positiviza. Ello es compatible con que el catálogo no sea exhaustivo -en rigor, con esa concepción de los derechos no sería necesario el artículo 72-, de modo que los jueces constitucionales están autorizados a descubrir nuevos derechos. ${ }^{24}$ La concepción también es coherente con entender que se trata de derechos absolutamente inviolables: dado que no han sido creados por una autoridad, no pueden ser suprimidos por una autoridad (Guastini, 2016:369).

El distinto alcance que se le ha atribuido a la expresión «derechos inherentes a la personalidad humana», asociándola al iusnaturalismo clásico, el derecho natural, las convicciones socialmente dominantes, la conciencia jurídica colectiva y los derechos humanos, se manifiesta en enunciados normativos que expresan los significados que recibe la disposición compleja del artículo 72. En otras palabras, las consecuencias normativas que se originan en la elaboración dogmática fueron cambiando su intensidad: de la lista de derechos que elaboraba Real a la incorporación de los sentidos normativos que se asignen a disposiciones de fuente internacional. ${ }^{25}$ La relevancia de la dogmática como origen de los derechos implícitos y la incorporación de contenidos normativos de fuente internacional al contenido constitucional son dos asuntos que requieren un mayor estudio, uno que recurra al análisis de la recepción judicial de estas construcciones dogmáticas que complementa la fuerte presencia del neoconstitucionalismo en el escenario dogmático y judicial.

Precisamente, una de las funciones centrales de la dogmática es proveer a los tribunales construcciones jurídicas; de algún modo, entonces, el éxito de la construcción dogmática se define en los tribunales. A la luz de los cambios en la interpretación del artículo 72, las decisiones judiciales que resuelven sobre la constitucionalidad de una ley recurriendo al contenido implícito del artículo 72: ¿son decisiones de aplicación de normas?, ¿o son decisiones de producción y justificación de normas que específicamente la Corte asigna como sentido normativo en cada caso? El reconocimiento por la dogmática de la actividad de construcción jurídica —-dogmática y jurisprudencial—en la identificación de derechos implícitos, pues, implica la aceptación de un desplazamiento de poderes normativos hacia los órganos jurisdiccionales que no siempre es consistente con la doctrina de las fuentes que por lo general se expresa en la literatura dogmática. Por otra parte, parece claro que los derechos implícitos pueden entrar en conflicto con los derechos expresamente enumerados. A la vez, no parece haber una directiva

ANUARIO DEL ÁREA SOCIO-JURÍDICA | MONTEVIDEO - URUGUAY | v. 10 | n. 1 | p. 01-15 | DEZ. 2018 
interpretativa de preferencia pacíficamente admitida en cuanto a que un derecho explícito deba ceder frente a un derecho implícito de fuente doctrinal o jurisprudencial (Guastini, 2014).

En este sentido, las consecuencias prácticas del alcance de la construcción jurídica pueden ilustrarse a través del siguiente ejemplo. Pensemos en una reciente decisión de la Suprema Corte de Justicia, como la sentencia 680/2017. ${ }^{26}$ Esta determina que los artículos 2 y 3 de la ley 18.831, que disponen -el primero- que no se computarán plazos de prescripción ya transcurridos y -el segundo- que, en forma retroactiva, a la naturaleza original del tipo penal se adicionará el carácter de crímenes de lesa humanidad, provocando como consecuencia su imposibilidad de extinción, vulneran ostensiblemente el principio de irretroactividad de la ley penal más gravosa, y con ello, los principios y reglas constitucionales recogidos en los artículos 10 y 72 de la Constitución. La justificación de la interpretación propuesta cita las elaboraciones dogmáticas de Real y Cajarville sobre el artículo 72. La posición discorde del ministro Hounie, que retoma la opinión de la mayoría de la Corte en una integración anterior, sostiene:

En relación con la imprescriptibilidad de los delitos de lesa humanidad [...], los artículos 2 y 3 de la ley 18.831 no modificaron el statu quo que las precedían, por cuanto ya se encontraban incorporadas en el sistema nacional de derechos humanos e ingresaban a nuestro ordenamiento por imperio del artículo 72 de la Constitución. Así, el artículo 72 de la Carta está dirigido no solo al reconocimiento de los derechos subjetivos de los seres humanos en forma individual, sino también al Estado, quien debe velar por ellos utilizando cualquier mecanismo que tienda a tal finalidad. El reconocimiento de esos delitos se encuentra en las normas de jus cogens que ingresan al sistema constitucional mediante la aplicación del artículo 72. La imprescriptibilidad de estos delitos también forma parte del sistema de tutela de los derechos fundamentales consagrados en el artículo 72 de la Constitución, ya que busca protegerlos de forma tal que sea imposible que quienes los perpetraron puedan sustraerse al castigo, al menos desde 1968, fecha en que fue aprobada la Convención sobre la Imprescriptibilidad de los Crímenes de Guerra y de los Crímenes de Lesa Humanidad por la Asamblea General de las Naciones Unidas.

La discordia recurre en apoyo de su opción interpretativa a la elaboración de Risso acerca del artículo 72. La Corte retoma, con la decisión de 2017, la posición que había tenido en 2013. La construcción jurídica recibida por el ministro discorde en 2013 fue luego tomada por la mayoría en 2016. En todos los casos, el artículo 72 formó parte de los argumentos normativos de la justificación de las decisiones de la Suprema Corte de Justicia vinculadas a la constitucionalidad de las disposiciones citadas de la ley 18.831.27

Apoyada en el dato de la inestabilidad de los acuerdos en el máximo tribunal, me permito conectar, para concluir, el carácter polémico y abierto de las respuestas jurídicas al problema de la violación de derechos humanos durante la última dictadura y los efectos de la Ley de Caducidad con una observación de Atria (2016). ${ }^{28}$ Las normas constitucionales que garantizan o reconocen derechos, dice Atria, no son normas respecto de las cuales alguien pueda, en casos políticamente relevantes, actuar como juez (2016:277), es decir, como tercero imparcial. El contenido de la disposición constitucional necesariamente se complementa con la concepción de los derechos - fundamentales, inherentes, humanos - del propio tribunal. De ese modo, los derechos constitucionales están en principio siempre disponibles para ser reinterpretados cuando las condiciones culturales o políticas cambian. La misma

ANUARIO DEL ÁREA SOCIO-JURÍDICA | MONTEVIDEO - URUGUAY | v. 10 | n. 1 | p. 01-15 | DEZ. 2018 
disposición constitucional puede significar cosas distintas e incluso opuestas, según la posición desde la que se le atribuya sentido. La plasticidad del lenguaje constitucional no es un asunto teórico, sino político (Atria, 2016:284).

\section{Referencias bibliográficas}

Atria, F. (2016). La forma del derecho. Madrid: Marcial Pons.

Bouvier, H. (2012). «La clase interpretadora». En Discusiones, XI, n. ${ }^{\circ} 11,167-176$.

Cajarville, J. P. (2001). «Reflexiones sobre los principios generales del derecho en la Constitución uruguaya». En Barbé Pérez et al. Los principios generales de derecho en el derecho uruguayo y comparado (131-154). Montevideo: Fundación de Cultura Universitaria.

Convención Nacional Constituyente (1916-1917) (1918). Diario de Sesiones, tomos I y III. Sesiones del 26 de octubre de 1916 al 5 de enero de 1917. Montevideo: Imprenta Nacional.

De Vega, P. (1985). La reforma constitucional y la problemática del poder constituyente. Madrid: Tecnos.

Guastini, R. (2012). Estudios sobre la Interpretación Jurídica. México: Porrúa - Unam.

- (2014). Interpretar y argumentar. Madrid: Centro de Estudios Políticos y Constitucionales.

- (2016). Las fuentes del derecho. Fundamentos teóricos. Lima: Editorial Científica Peruana - Raguel Ediciones. Hesse, K. (1983). Escritos de derecho constitucional (selección). Madrid: Centro de Estudios Constitucionales. Jiménez de Aréchaga, J. (1946). La Constitución nacional, I. Montevideo: Medina.

López Cadena, C. (2009). «Aproximación a un concepto normativo de mutación de los derechos». Revista Derecho del Estado, 22 (junio), 129-158.

Nogueira, H. (2003). «Los derechos esenciales o humanos contenidos en los tratados internacionales y su ubicación en el ordenamiento jurídico nacional: doctrina y jurisprudencia». Ius et Praxis, 9 (1), 403-466.

Real, A. R. (1974). Estado de derecho y humanismo personalista. Montevideo: Fundación de Cultura Universitaria.

- (1979). «Los métodos de interpretación constitucional». Revista de Derecho Público, 25/26, 56-69.

- (2001). «Los principios generales de derecho en la Constitución uruguaya. Vigencia de la estimativa jusnaturalista». En Barbé Pérez et al. Los principios generales de derecho en el derecho uruguayo y comparado (33-81). Montevideo: Fundación de Cultura Universitaria.

Risso, M. (2015). La Constitución uruguaya de 1967. Balance y perspectivas. Montevideo: Universidad Católica del Uruguay.

- (2017). «Mutación e interpretación evolutiva de la Constitución». Estudios Constitucionales, 15, n. 1 , 217-254.

Rollnert Liern, G. (2014). «La mutación constitucional, entre la interpretación y la jurisdicción constitucional». Revista Española de Derecho Constitucional, 101, 125-155.

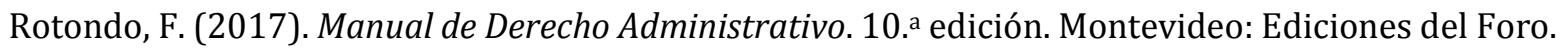

Sampay, A. E. (1957). La declaración de inconstitucionalidad en el derecho uruguayo. Montevideo: Medina.

Sarlo, Ó. (2011). «Derechos, deberes y garantías implícitos en la Constitución uruguaya. Un análisis de filosofía política y epistemología del derecho». En Estudios jurídicos en homenaje al profesor Juan Pablo Cajarville Peluffo (1069-1099). Montevideo: Fundación de Cultura Universitaria. 
Silva Ledesma, F. (1977). Incidencia de los Actos Institucionales en el ordenamiento constitucional uruguayo. Montevideo: Ministerio de Relaciones Exteriores, Instituto Artigas del Servicio Exterior.

Uprimny, R. (2008). Bloque de constitucionalidad, derechos humanos y derecho penal. Bogotá: Consejo Superior de la Judicatura - Universidad Nacional de Colombia.

- (2011). «Las transformaciones constitucionales recientes en América Latina: tendencias y desafíos». En C. Rodríguez Garavito (coord.). El derecho en América Latina: un mapa para el pensamiento jurídico en el siglo XXI. Buenos Aires: Siglo Veintiuno Editores.

\section{Notas}

1 Es el caso de la reforma constitucional de 1994 en Argentina, que en el numeral 22 de su artículo 75 establece una lista de tratados sobre derechos humanos que adquieren jerarquía constitucional.

2 Como en el caso de la Constitución de Brasil.

3 Es el caso de la Constitución colombiana de 1991.

${ }^{4}$ Sigo la reconstrucción historiográfica planteada por Sarlo (2011), con el correspondiente cotejo del Diario de Sesiones de la Convención Nacional Constituyente.

5 El texto incluye, para la mayor parte de las disposiciones proyectadas, una nota al pie de fundamentación. El artículo 149 no incluye nota al pie alguna.

${ }^{6} \mathrm{Al}$ cierre de la nota, expresa: «Yo me consideraría feliz si con el acuerdo patriótico de todos llegáramos a sancionar aquellas [modificaciones] que afectan profundamente la suerte de nuestro país, y lográramos especialmente asentar de manera sólida la libertad de sufragio y la independencia de los poderes públicos, bases fundamentales del gobierno republicano» (Convención Nacional Constituyente, 1918 [tomo I]:200). Destacado nuestro.

7 En la sesión de 3 de enero de 1917 se incorpora el proyecto remitido el 29 de diciembre anterior por el convencional por Colonia, Horacio Jiménez de Aréchaga. El artículo 211 tiene casi la misma redacción que el proyecto de Vásquez Acevedo: «La enumeración de derechos y garantías hecha por la Constitución no excluye los otros que son inherentes a la personalidad humana o se derivan de la forma republicana de gobierno» (Convención Nacional Constituyente, 1918 [tomo I]:454).

8 Partido Colorado.

9 «Su mejor defensa consiste en los bellísimos principios que proclama, sintetizando las conquistas alcanzadas por el espíritu humano en sus luchas por la libertad y las garantías de que rodea el ejercicio de los sagrados derechos del hombre. Hemos leído, a propósito de comentarios de algunas constituciones, que eran sumamente recomendables por la grandeza de sus declaraciones dogmáticas, por la riqueza y abundancias de sus garantías a su derecho político. Será así, pero el proyecto, lo aseguramos sin temor de errar, no cede un ápice a esas cartas monumentales en cuanto a consagrar libertades, derechos y garantías. Los que se dignen estudiarlo para dar una opinión fundada dirán si estamos o no en lo cierto» (Convención Nacional Constituyente, 1918 [tomo I]:252).

10 Dejo anotado el interés por volver a cotejar las diferencias filosófico-políticas de la redacción de la cláusula de derechos implícitos aprobada y la del proyecto de Azarola, el que, en principio, acotaba a las fuentes

ANUARIO DEL ÁREA SOCIO-JURÍDICA | MONTEVIDEO - URUGUAY | v. 10 | n. 1 | p. 01-15 | DEZ. 2018 
sociales la identificación de los principios y garantías implícitas mediante una redacción similar a la propuesta en la Constituyente argentina de 1860 (ver nota siguiente).

11 En la fundamentación, con relación al artículo 173, establece: «Hamilton, en El Federalista, explicando la grave omisión de la Constitución de los Estados Unidos de 1787 respecto a la declaración de derechos y garantías, afirmaba que prefirieron no haber dicho nada antes que hacer una enumeración incompleta de aquellos. Las primeras enmiendas efectuadas a la Constitución americana evitan la crítica hecha por Hamilton. Formulan, por considerarla imprescindible salvaguardia de las libertades individuales, una declaración de derechos y garantías, pero enseguida establece [...] este precepto: "No se dará jamás a la enumeración de los derechos de esta Constitución consignados una interpretación que niegue o derogue los que se hayan reservado". En la Constituyente argentina de 1860, inspirados en el ejemplo americano, se propuso el artículo 33, que dice así: "Las declaraciones, derechos y garantías que enumera la Constitución no serán entendidos como negación de otros derechos y garantías no enumerados, pero que nacen del principio de la soberanía del pueblo y de la forma republicana de gobierno". Este artículo —análogo al que Vuestra Comisión os proponefue defendido en la Constituyente de 1860 por los hombres más esclarecidos de la República Argentina: pugnaron por su triunfo Mitre, Sarmiento y Vélez Sarsfield. Es al amparo de esa disposición que ha podido defenderse en toda su amplitud el derecho de reunión, pues aun cuando no esté consignado en la Constitución argentina - como no lo está en la nuestra de modo expreso-, es un derecho que no puede ser negado, porque nace del principio de la soberanía del pueblo y de la forma republicana de gobierno» (Convención Nacional Constituyente, 1918 [tomo III]:401).

12 En la Constitución de 1934, en consonancia con la modificación del título de la sección II («Derechos, deberes y garantías»), la redacción de la disposición agregó el término «deberes» al artículo 173 de 1917, y esa es la redacción que se mantiene incambiada hasta la Constitución vigente.

13 Ver Sarlo (2011) para un perfil del autor argentino.

14 Es la fuente del proyecto de Azarola.

15 El Estado de derecho, dice Real, en su concepción original, supone la organización del gobierno en función de la tutela de los derechos individuales que, a su vez, son entendidos como límites naturales, preexistentes y objetivos frente al Estado. En ese sentido, son reconocidos o declarados - no creados-, y solo puede regulárselos por ley, por razones de interés general (1974:143). Es esta concepción filosófica —la teoría clásica del derecho natural- la que propone como guía de la interpretación (como principio general). Sin embargo, es interesante que sea precisamente en 1974 que, a continuación de esas consideraciones acerca de la validez absoluta de esos derechos y su normatividad como límite al legislador, señala: «Más allá de la Constitución, frente al poder constituyente, dotado de competencia para modificar la Constitución misma, ya no cabe hablar de garantías jurídicas de fondo: las garantías serán sociales y políticas, y dependerán, en último término, del sentimiento del derecho y del espíritu cívico del pueblo; incluso de su capacidad para resistir, llegado el caso, a la opresión. La teoría jurídica [...] no puede pretender suplantar al pensamiento social de cada época y considerar derecho vigente por encima del poder constituyente a los diversos, cambiantes y vagos sistemas de valores que proclame hoy, con arrogancia, cada jurista. Admitirlo sería reincidir en la ilusión del iusnaturalismo» (1974:144). La naturaleza dogmática de sus afirmaciones se concreta en el siguiente párrafo: «El tipo del Estado de derecho en sentido material o técnico que describimos es, pues, y solo puede ser, con posibilidades científicas, la descripción de los rasgos generales de una forma o de ciertas formas históricas, concretas, de organización gubernativa, concebidas en función de una idea personalista de los fines del Estado 
que políticamente compartimos, pero que no podemos pretender imponer, como obligación jurídica, a los constituyentes futuros de todos los tiempos y lugares» (1974:144-145).

16 En ese sentido, concluye que la interpretación teleológica contribuye «a la permanencia, vitalidad y dinamismo de la Constitución, al adecuar, racionalmente, la solución de los casos concretos a los principios cardinales de la organización y, en especial, a la ideología o filosofía del régimen político, democráticorepublicano» (Real, 1979:69).

17 Aclara Real que adopta la terminología de Recasens Siches, quien distingue el personalismo y el transpersonalismo como las principales posiciones respecto del fin del Estado.

18 También aclara que la noción personalista de los fines del Estado que propone «no debe confundirse con el individualismo llamado liberal-burgués, que reduce el fin del Estado a la mera tutela de la libertad y del derecho de los individuos sin tratar de atenuar o eliminar las desigualdades injustas en lo económico y social», que remite a la justa distribución de las cargas públicas y a «una concepción amplia del personalismo [...], [que eleva] las condiciones de vida del mayor número posible de habitantes, en todos los aspectos, aun ensanchando el ámbito de los fines del Estado, en función de una nueva y más generosa concepción de los derechos del hombre, que impone a la comunidad organizada la prestación de servicios positivos a los habitantes, como suministrarles asistencia, instrucción, jubilaciones y pensiones, seguros sociales, asignaciones familiares, etc.» (Real, 1974:126-127). Es decir: tutela negativa y tutela positiva de los derechos.

19 Estos principios, distintos de los del artículo 72, se aplican supletoriamente por falta de reglamentación de las disposiciones constitucionales que reconocen derechos a los individuos y confieren facultades o imponen deberes a las autoridades, de forma de hacerlas aplicables (Cajarville, 2001:134). Agrega, citando a Cassinelli en cuanto a los principios que reconocen derechos en virtud del artículo 72, que tampoco dejan de aplicarse por falta de reglamentación, de modo que «para suplirla, se acudirá a esos mismos principios (conjuntamente con los fundamentos de las leyes análogas y las doctrinas generalmente admitidas)» (Cajarville, 2001:134).

20 La determinación de los derechos implícitos se remite, en definitiva, a la moral social.

21 La noción de mutación constitucional, que no tiene casi desarrollo en Uruguay —ni en el campo dogmático ni en el jurisdiccional一, es entendida como «un cambio en el contenido normativo de una disposición sin que se advierta ninguna alteración en su tenor literal», por lo cual, pueden considerarse reformas informales de la Constitución (López Cadena, 2009:130). De alguna manera, se trata de operaciones interpretativas en detrimento de la rigidez constitucional o que la vulneran.

22 Presidente del Supremo Tribunal Militar entre 1974 y 1985.

23 En sus comentarios al acto institucional número 2, afirma: «Se entiende que el poder constituyente radica en el Poder Ejecutivo, que es quien [lo] tiene en este período de crisis, en esta situación de emergencia. Decíamos [...] que el estado de necesidad, si lo consideramos principio de derecho, podría estar comprendido dentro de lo que establece el artículo 72 de la Constitución vigente; ese poder constituyente que se atribuye el Poder Ejecutivo estaría dentro del marco de las previsiones del artículo 72» (Silva Ledesma, 1977:28). Agradezco al Prof. Felipe Rotondo haberme señalado esta publicación.

${ }^{24}$ Salvando las distancias, y a propósito de lo problemático de pensar este tipo de disposiciones como una apertura a principios y valores que serían parte de un eventual bloque de constitucionalidad, con miras a destacar la importancia de la elaboración de una dogmática clara sobre el alcance de la categoría bloque de constitucionalidad, Uprimny menciona a la Constitución de Venezuela de 1999, que establece que esa república «fundamenta su patrimonio moral y sus valores de libertad, igualdad, justicia y paz internacional en la doctrina de Simón Bolívar, el Libertador» (Uprimny, 2008). La disposición referida, dice Uprimny, podría entonces llevar 
a algunos intérpretes a considerar que la doctrina de Bolívar fue constitucionalizada — como la doctrina uruguaya sostiene que ocurre con el iusnaturalismo-, y que «todas sus cartas, discursos y proclamas forman parte del bloque de constitucionalidad, lo cual generaría evidentes riesgos en términos de seguridad jurídica y arbitrariedad judicial. Así, un operador jurídico podría invocar la Carta de Jamaica de Bolívar como argumento constitucional, mientras que otro podría recurrir al discurso del Libertador en el Congreso de Angostura, con lo cual el debate constitucional podría tornarse inmanejable» (Uprimny, 2008:37).

25 El alcance normativo de estas disposiciones es, a su vez, determinado por los órganos de los tratados de derechos humanos.

26 En la sentencia 680/2017, de 25 de setiembre de 2017, la Suprema Corte de Justicia, por mayoría de sus integrantes, declaró inconstitucionales los artículos 2 y 3 de la ley 18.831, de 27 de octubre de 2011, estableciendo con ello un cambio jurisprudencial respecto de las decisiones adoptadas por la Corte en 2016, también por mayoría de sus integrantes.

27 Si asumimos que la ponderación consiste en establecer una jerarquía entre dos principios o derechos en conflicto, esa jerarquía es, al mismo tiempo, axiológica y móvil, en tanto supone, por un lado, una relación de valor creada no por las fuentes, sino por el tribunal, mediante un juicio de valor comparativo que resulta en la atribución a un principio o derecho de una importancia ético-política mayor (Guastini, 2016:342-343); y por otro, que tal jerarquización es válida para el caso concreto (Guastini, 2016:344). Teniendo en cuenta lo anterior, es claro que la ponderación implica el ejercicio de una doble discrecionalidad: la creación de una jerarquía axiológica y el cambio de valor comparativo de los mismos principios o derechos en distintas oportunidades (Guastini, 2016:344-345). A su vez, al igual que la identificación de derechos implícitos, la ponderación «pertenece al dominio de la construcción jurídica». La decisión acerca de la inconstitucionalidad requiere decidir que uno de dos de los derechos implícitos en el artículo 72 debe ser priorizado. La solución se construye ocultando la ponderación y procurando reconducir el razonamiento a la aplicación de una regla tal que no pueda concluirse que el principio de irretroactividad de la ley se deja de lado por una opción política o moral del decisor.

28 Recordemos que otros argumentos de tipo neoconstitucionalista - los vinculados a la noción de esfera de lo indecidible, propuesta por Ferrajoli- fueron empleados por la Suprema Corte de Justicia en 2009 (sentencia 365/2009), junto con la doctrina del bloque de constitucionalidad, para declarar inconstitucionales los artículos 1, 3 y 4 de la ley 15.848, de caducidad de la pretensión punitiva del Estado, y por la Corte Interamericana de Derechos Humanos en el caso Gelman vs. Uruguay para fundar la inoponibilidad de los efectos de la Ley de Caducidad (sentencia de 24 de febrero de 2011). 